\title{
EFISIENSI PEMASARAN IKAN KAKAP MERAH (Lutjanus argentimaculatus) DI WILAYAH KERJA TPI KARANGSONG, KABUPATEN INDRAMAYU
}

\author{
Uswatun Hasanah ${ }^{1}$, Wiwik Ambarsari ${ }^{2}$, dan Wawan Gunawan ${ }^{3}$ \\ ${ }^{1,2}$ Program Studi Agribisnis Fakultas Pertanian Universitas Wiralodra , J1 Ir. H. Djuanda Km 3 Indramayu, \\ uswatunhasanah@gmail.com, wiwikambarsari@yahoo.co.id \\ ${ }^{3}$ Program Studi Agroteknologi Fakultas Pertanian Universitas Wiralodra, J1 Ir. H. Djuanda Km 3 Indramayu, \\ Indonesia, wawangunawan@unwir.ac.id
}

Diterima 20 Agustus 2019, disetujui 28 September 2019, diterbitkan 31 Oktober 2019

Pengutipan: Hasanah, U, Ambarsari, W \& Gunwawan, W. (2019). Efisiensi Pemasaran Ikan Kakap Merah (Lutjanus Argentimaculatus) di Wilayah Kerja TPI Karangsong, Kabupaten Indramayu. Gema Wiralodra, Vol 10, No 2, Hal 307-319, Oktober 2019

\begin{abstract}
ABSTRAK
Potensi Ikan Kakap Merah sangat tinggi di TPI Karangsong, namun nelayan bukan penentu harga. Penelitian ini bertujuan untuk mengetahui efisiensi pemasaran Ikan Kakap Merah (Lutjanus argentimaculatus) melalui saluran pemasaran dan fungsi-fungsi yang dilakukan oleh pelaku lembaga pemasaran Ikan Kakap Merah di wilayah kerja TPI Karangsong. Metode yang digunakan survey dengan pendekatan deskriptif. Analisis data dilakukan secara deskriptif kuantitatif dan kualitatif. Pengambilan sampel sebagai responden dilakukan secara simple random sampling (SRS), terdiri atas 23 orang nelayan. Responden lembaga pemasaran berjumlah 5 pedagang besar dan 11 pedagang pengecer yang diperoleh dari cara snowball sampling. Hasil penelitian menunjukkan bahwa terdapat empat saluran pemasaran Ikan Kakap. Pola saluran pemasaran I : nelayan-TPI-pedagang besarpengecer-konsumen, margin pemasaran $\mathrm{Rp} 45.284,-/ \mathrm{kg}$, biaya pemasaran $\mathrm{Rp} 2.775,-/ \mathrm{kg}$, keuntungan Rp 42.509,-/kg, fishman's share 87,23\%, dan Ep 6,05\%. Pola saluran pemasaran II : nelayan-TPIpedagang besar-rumah makan daerah, margin pemasaran $\mathrm{Rp} 49.427,-/ \mathrm{kg}$, biaya pemasaran $\mathrm{Rp}$ 2.626,-/kg, keuntungan Rp 46.801,-/kg, fishman's share 80,00\%, dan Ep 5,25\%. Saluran pemasarn III ; nelayan-TPI-pedagang besar-pengecer luar daerah-konsumen, margin pemasaran Rp 54.427,$/ \mathrm{kg}$, biaya pemasaran Rp 3.232,-, keuntungan Rp 51.192,-/kg, fishman's share 81,82\%, dan Ep $5,88 \%$. Saluran pemasaran IV : nelayan-TPI-pedagang besar- rumah makan luar daerah, margin pemasaran Rp 59.427,-/kg, biaya pemasaran Rp 3.033,-/kg, keuntungan Rp 56.394,-/kg, fishman's share 75,00\%, dan Ep 5,06\%. Kesimpulan penelitian ini adalah saluran pemasaran paling efisien pada pola saluran pemasaran I. Saran bagi nelayan perlu membentuk kelompok dan kopersai nelayan agar memiliki bargaining power sebagai penentu harga.
\end{abstract}

Kata kunci: efisiensi pemasaran, ikan kakap, TPI Karangsong

\begin{abstract}
This study aims to determine the marketing efficiency of Red Snapper Fish ((Lutjanus argentimaculatus) through marketing channels and fuctions carried out by Red Snapper marketing institutions in the TPI Karangsong working area. The method used in the survey was a descriptive approach. Data analysis was performed descriptively quantitative and qualitative. Sampling as a respondent was carried out by sample ransom sampling (SRS), consisting of 23 fishmen. Marketing agency respondents number 5 large traders and 11 retailer obtained from snowball. The result showed that there were four red snapper fish marketing channels in the working area of TPI Karangsong, Indramayu Regency. Pola marketing channel I : fishmen-TPI-big traders -pengecer-consumen, marketing margin IDR45.284,-/kg, marketing cost IDR 2.775,-/kg, benefit IDR 42.509,-/kg, fishman's share 87,23\%, dan Ep 6,05\%. Pola marketing channel II: fishmen-TPI- big trader- rumah makan daerah, marketing margin IDR 49.427,-/kg, marketing cost IDR Rp 2.626,-/kg, benefit IDR 46.801,-/kg, fishman's share 80,00\%, dan Ep 5,25\%. Pola marketing channel III: fishmen-TPI-big traders-pengecer luar daerah-consumen, marketing margin IDR 54.427,-/kg, marketing cost IDR $3.232, / \mathrm{kg}$-, benefit IDR 51.192,-/kg, fishman's share $81,82 \%$, dan Ep 5,88\%. Pola saluran pemasaran IV: fishmen-TPI-big traders- rumah makan luar daerah, marketing margin IDR 59.427,-/kg, marketing cost IDR 3.033,-/kg, benefit IDR 56.394,-/kg, fishman's share 75,00\%, dan Ep 5,06\%. Conclution of this study was marketing channel the most efficiet on the marketing channel I,
\end{abstract}


fishmen's share $87,23 \%$ Suggestions on fishmens to groups an fishmen koperasi so It has bargaining power as price maker.

Keywords: marketing efficiency, red snapper fish, TPI Karangsong

\section{PENDAHULUAN}

Kabupaten Indramayu adalah salah satu wilayah dengan kondisi ekologis dan geografis yang potensial untuk pengembangan usaha perikanan dan kelautan yang menyeluruh, meliputi perikanan tangkap, perikanan budidaya, pengolahan hasil perikanan dan kelautan dan produksi garam rakyat. Dengan potensi yang dimiliki, maka Kabupaten Indramayu memiliki kontribusi perikanan dan kelautan terbesar di Propinsi Jawa Barat, yaitu kegiatan perikanan tangkap meliputi penangkapan ikan di laut dan di perairan umum (Dinas Perikanan dan Kelautan Kabupaten Indramayu, 2012).

Sesuai dengan letaknya yang berada di pesisir pantai, Indramayu merupakan salah satu Kabupaten penghasil ikan. Produksi ikan laut segar selama tahun 2011 sampai dengan tahun 2013 terus mengalami kenaikan, dengan pertumbuhan y sebesar 11,02 persen. Hasil tangkap ikan sebanyak 128.548 ton dan nilai tangkap sebesar Rp 1.829.994.727 tahun 2013 (Dinas Perikanan dan Kelautan Kabupaten Indramayu, 2014).

Kakap Merah merupakan salah satu jenis ikan hasil tangkapan laut yang ada di TPI Karangsong Kabupaten Indramayu. Jumlah produksi Kakap Merah di TPI Karangsong sepanjang tahun 2015 mengalami fluktuasi, dikarenakan produksi ikan di laut tidak bisa diprediksi dan juga tergantung musim. Jumlah produksi paling besar mencapai 45.527 kilogram, yaitu terjadi pada bulan November, sedangkan jumlah produksi terendah sebesar $14.955 \mathrm{~kg}$ terjadi pada bulan Oktober. Hal ini dikarenakan pada bulan Oktober cuaca yang buruk dan tidak memungkinkan nelayan untuk menangkap ikan. Nilai produksi Ikan Kakap Merah tahun 2015 di TPI Karangsong sebesar Rp 12.074.125.000 (Koperasi Perikanan Laut Mina Sumitra, 2015).

Kakap merah sangat digemari masyarakat, memiliki nilai ekonomis tinggi karena memiliki kualitas daging tebal, putih, empuk dan rasa yang gurih, memiliki kandungan gizi yang bermanfaat bagi kesehatan tubuh, dan harga cukup tinggi. Harga rata rata Ikan Kakap Merah pada tahun 2015 yaitu berkisar antara Rp 34.425 per kilogramnya di TPI Karangsong (Koperasi Perikanan Laut Mina Sumitra, 2015). Huda, et al. (2016) mengungkapkan bahwa harga Ikan Kakap Merah terbentuk dari lembaga-lembaga pemasaran yang terlibat, yaitu nelayan, distributor, pedagang ikan di pasar regional, pedagang di pasar kabupaten, dan pedagang di pasar kecamatan/desa dan meraka berlomba-lomba mempertahankan kualitas ikan yang mengakibatkan margin harga ikan sendiri. Awalnya harga disebabkan dimulai dari 
harga penjualan di TPI. Biaya pemasaran juga terjadi di pihak distributor yang menyebabkan terjadinya margin karena harus mengeluarkan biaya-biaya lain pula. Biaya yang dikeluarkan meliputi membayar jasa pikul dari TPI menuju pickup, pemberian es untuk ikan, biaya bahan bakar minyak kendaraan, upah sopir, pengambilan keuntungan, biaya retribusi pembelian ikan dari TPI dan biaya resiko. Selain itu, terdapat biaya dalam menangani dan mengambil keuntungan harus diperoleh oleh pedagang di pasar regional, pasar kabupaten dan pasar kecamatan. Tingginya potensi Ikan Kakap Merah di TPI Karangsong yang dapat memberikan pendapatan tinggi pada nelayan, namun nelayan bukan menjadi penentu harga pada saat pemasaran berlangsung. Apakah pemasaran ikan pada saluran pemasaran dapat memberikan adil pada nelayan? Bagaimana pemasaran ikan kakap memberikan bagian yang besar bagi nelayan (fisherman's share) dari harga yagn dibayarkan konsumen? Harapannya pada nelayan agar pemasaran ikan pada salurannya efisien dan dapat memberikan harga tinggi bagi nelayan. Konsumen pun berharapk yang sama, bagaimana konsumen mendapatkan harga yang murah melalui pemasaran ikan kakap yang efisien. Mengingat bahwa proses pemasaran nelayan dari hasil tangkapnya sering mendapat kendala yang dapat menyebabkan pada panjangnya saluran pemasaran sehingga produk sampai ke konsumen menjadi lebih lama, biaya pemasaran menjadi tinggi, dan margin pemasaran tinggi pula. Semakin besar selisih harga jual nelayan dengan harga yang dibayarkan konsumen akhir akan semakin tidak efisien.

Mubyarto (1994) mengungkapkan bahwa sistem pemasaran dianggap efisien jika mampu memberikan pembagian yang adil dari keseluruhan harga yang dibayarkan konsumen akhir kepada semua pihak yang terlibat dalam kegiatan pemasaran. Hasil penelitian Giamurti, et al.(2015) mengungkapkan bahwa nilai fisherman's share sebesar $95,65 \%$, artinya bahwa nelayan memperoleh harga sebesar 95,65\% dari harga yang dibayarkan konsumen dan nilai efisiensi pemasaran sebesar 0,03 adalah tertinggi pada pedagang pengumpul di Pelabuhan Perikanan Nusantara Brondong, Lamongan, Jawa Timur. Dengan demikian tujuan penelitian ini adalah untuk mengetahui efisiensi pemasaran Ikan Kakap Merah (Lutjanus argentimaculatus) di wilayah kerja TPI Karangsong, Kabupaten Indramayu.

\section{METODE PENELITIAN}

Penelitian ini dilakukan di wilayah kerja Tempat Pelelangan Ikan (TPI) Karangsong Desa karangsong Kecamatan Indramayu Kabupaten Indramayu pada bulan Mei tahun 2016. 
Lembaga pemasarannya yaitu pedagang besar, dan pedagang pengecer yang terlibat pada proses pemasaran Ikan Kakap Merah.

Metode yang digunakan dalam penelitian ini adalah metode survei dengan pendekatan deskriptif yaitu penyelidikan yang diadakan untuk memperoleh fakta-fakta dari gejala-gejala yang ada dan mencari keterangan-keterangan secara aktual, baik tentang intuisi sosial, ekonomi, atau politik dari suatu kelompok ataupun suatu daerah (Nazir, 2011).

Jenis data yang digunakan dalam penilitian ini adalah data primer dan data sekunder. Data primer dari hasil wawancara langsung dengan nelayan dan pedagang Ikan Kakap Merah, sedangkan data sekunder diperoleh dari berbagai sumber pustaka dan literaturliteratur yang dikeluarkan oleh lembaga-lembaga maupun instansi, seperti Dinas Perikanan dan Kelautan Kabupaten Indramayu, Koperasi Perikanan Laut Mina Sumitra Indramayu, hasil penelitian yang telah dilakukan.

Teknik penentuan sampel penelitian, yaitu pada populasi responden nelayan Ikan Kakap Merah di TPI Karangsong sebanyak 47 orang. Penentuan responden nelayan dalam sampel penelitian ini dilakukan dengan menggunakan teknik acak sederhana atau Simpel Random Sampling (SRS) yang didasarkan atau rumusan dari Nazir (2011), yaitu sebagai berikut :

$\mathrm{n}=\frac{N \cdot p(1-p)}{(N-1) \frac{B^{2}}{4}+p(1-p)}$

Keterangan :

$\mathrm{n}=$ ukuran sampel (jumlah responden)

$\mathrm{N}=$ ukuran populasi (jumlah nelayan tangkap Kakap Merah) 47 orang

$\mathrm{p}=$ proporsi $(0,5)$

$\mathrm{B}=$ batas kesalahan $($ bound of error $)=15 \%=0,15$

Berdasarkan perhitungan maka sampel responden nelayan berjumlah 23 orang. Pada penelitian ini diperoleh sampel lembaga pemasaran Ikan Kakap Merah terdiri dari 5 pedagang besar dan 11 pedagang pengecer dengan cara snowball sampling yaitu teknik penentuan sampel yang mula-mula jumlahnya kecil, kemudian sampel ini disuruh memilih temantemannya untuk disajikan sampel begitu seterusnya sehingga jumlah sampel semakin banyak (Sugiono, 2009). Teknik pengumpulan data dalam penelitian ini adalah observasi dan wawancara dengan menggunakan kuesioner pada responden nelayan dan lembaga pemasaran. 


\section{Analisis Data}

Data hasil wawancara pada responden nelayan, pedagang besar, dan pedagang pengecer dilakukan analisis data secara deskriptif kualitatif dan kuantitatif. Deskriptif kualitatif diperoleh pola saluran pemasarannya bersamaan dengan lembaga-lembaga pemasaran di dalamnya. Deskriptif kuantitatif berdasarkan data fungsi-fungsi kelembagaannya diperoleh margin pemasaran, farmer's share, dan efisiensi pemasaran.

\section{Margin pemasaran}

Rahim dan Hastuti (2007) menyatakan margin pemasaran didefinisikan selisih harga yang dibayarkan di tingkat konsumen dengan harga yang diterima oleh produsen, rumus :

$$
\mathrm{MP}=\mathrm{Pr}-\mathrm{pf}
$$

Dimana :

MP = Margin pemasaran pada lembaga pemasaran ke-i

Pr = Harga di tingkat konsumen $(\mathrm{Rp})$

$\mathrm{Pf}=$ Harga di tingkat produsen $(\mathrm{Rp})$

Menurut Sudiyono (2004) untuk mengetahui keuntungan yang diperoleh oleh setiap lembaga pemasaran dapat dilihat dari margin dan biaya, secara matematis dapat dirumuskan sebagai berikut :

Dimana :

$$
\mathrm{Mj}=\mathrm{Cij}+\pi \mathrm{i}
$$

$\mathrm{Mj}=$ margin pemasaran pada lembaga pemasaran ke-i

$\mathrm{Cij}$ = biaya pemasaran untuk melaksanakan fungsi pemasaran ke-i oleh lembaga pemasaran ke-j (Rp)

$\pi \mathrm{i}=$ keuntungan lembaga pemasaran ke-i (Rp)

\section{Farmer's share}

Harga yang diterima produsen dan dibandingkan harga yang dibayar konsumen disebut dengan farmer's share dan dinyataan dalam persentase, menurut Rahim dan Hastuti (2007) secara matematis dirumuskan dengan sebagai berikut:

$$
\mathrm{Fs}=\frac{P f}{P r} \times 100 \%
$$

Dimana:

Fs = Bagian yang diterima nelayan

$\mathrm{Pf}=$ Harga di tingkat nelayan $(\mathrm{Rp} / \mathrm{kg})$

$\operatorname{Pr}=$ Harga ditingkat konsumen akhir $(\mathrm{Rp} / \mathrm{kg})$

\section{Efisiensi Pemasaran}

Mencari Efisiensi Pemasaran menurut Soekartawi (2002) yaitu :

$$
\mathrm{Ep}=\frac{\text { Biaya Pemasaran }}{\text { Nilai Produksi yang dipasarkan }} \times 100 \%
$$


Dimana

Ep $=$ Efisiensi Pemasaran

Bila Ep $<50 \%$, maka pemasaran efesien

Bila Ep $>50 \%$, maka pemasaran belum efesien

\section{HASIL DAN PEMBAHASAN \\ Saluran Pemasaran}

Saluran pemasaran Ikan Kakap Merah yang berawal dari Tempat Pelelangan Ikan (TPI) Karangsong Kabupaten Indramayu dimulai dengan nelayan yang menjual hasil tangkapanya melalui sistem lelang yang dikelola oleh KUD Mitra Sumitra kepada pedagang besar, kemudian pedagang besar menyalurkannya kepada pedagang pengecer dan rumah makan yang berada di daerah dan luar daerah yaitu Jakarta. Saluran pemasaran yang terbentuk terdiri dari 4 pola saluran. Pada keempat pola saluran pemasaran ini selalu mengikut sertakan TPI dalam lembaga pemasaran. Purnomo (2018) menyatakan bahwa TPI menjadi mediator yang selalu dilibatkan dalam transaksi penjualan pada semua pola antara nelayan dengan pelaku pemasaran berikutnya.

\section{Saluran Pemasaran I}

Saluran pemasaran I terdiri dari : nelayan $\rightarrow$ TPI $\rightarrow$ pedagang besar $\rightarrow$ pedagang pengecer $\rightarrow$ konsumen. Saluran pemasaran Ikan Kakap Merah pertama ini menggunakan tiga lembaga pemasaran diantara nelayan dan konsumen, yaitu Tempat Pelelangan Ikan (TPI), pedagang besar, dan pengecer. Umumnya, pengecer membeli ikan kakap dari pedagang besar yang langsung dijual lagi kepada konsumen. Pedagang pengecer akan membeli ikan jauh lebih mahal dari pada pedagang besar yang langsung di TPI melalui sistem lelang. Hal ini dikarenakan jumlah yang dibeli jauh lebih besar pedagang besar dibandingkan pengecer. Jumlah Ikan Kakap Merah yang diperjualbelikan pada saluran pertama ini berjumlah $75 \mathrm{~kg}$. Harga beli pengecer sebesar Rp 42.000,-/kg sedangkan harga beli pedagang besar Rp 40.000,-/kg. Kualitas Ikan Kakap yang dijaul belikan pada level kualitas kedua.

\section{Saluran Pemasaran II}

Saluran pemasaran II terdiri dari : nelayan $\rightarrow$ TPI $\rightarrow$ pedagang besar $\rightarrow$ rumah makan daerah. Saluran Ikan Kakap Merah kedua, terdapat dua lembaga pemasaran antara nelayan dan rumah makan daerah,yaitu TPI dan pedangang besar. Sama halnya pada saluran pertama bahwa ikan yang diperjualbelikan pada level kualitas kedua dengan harga Rp $40.000,-/ \mathrm{kg}$ yang dibeli oleh pedagang besar dari TPI, pada saluran kedua ini berjulah 15 ekor. Pada saluran kedua ini pedagang besar menjual ikanya kepada rumah makan daerah 
yang harganya jauh lebuh tinggi dibandingkan di tingkat pengecer pada saluran pertama.Hal ini dikarenakan rumah makan akan diolah lagi melalui proses yang memakan biaya proses produksinya sehingga jauh lebih tinggi harga yang dijual dibandingkan pada pengecer yang langsung menjual ikannya kepada konsumen tanpa proses pengolahan.

\section{Saluran Pemasaran III}

Saluran pemasaran III terdiri dari : nelayan $\rightarrow$ TPI $\rightarrow$ pedagang besar $\rightarrow$ pedagang pengecer luar daerah $\rightarrow$ Konsumen. Pada saluran pemsaran Ikan Kakap ketiga ini terdiri atas tiga lembaga pemasaran diantara nelayan dan konsumen, yaitu TPI, pedagang besar dan pedagang pengecer luar daerah. Pada level ini, Ikan Kakap yang diperjualbelikan pada level pertama dengan kualitas terbaik seharga $\mathrm{Rp} 45.000,-/ \mathrm{kg}$ sehingga harga perkilogramnya lebih tinggi dibandingan di level kedua $\mathrm{Rp} 40.000,-/ \mathrm{kg}$ di tingkat TPI. Sasaran pemasarannya pun keluar kota sehingga diperlukan kualitas primer agar sampai ke tempat tujuan dengan kondisi prima pula. Ikan Kakan Merah yang diperjualbelikan di saluran ketiga ini berjumlah $190 \mathrm{~kg}$. Pedangang pengecer luar daerah membeli dari pedangan besar sebesar Rp 50.000,$/ \mathrm{kg}$ dan pengecer luar daerah menjualnya Rp 55.000,-/kg. Tingginya harga jual pengecer luar daerah dikarenakan biaya operasional yang dikeluarkan untuk menjual ke luar daerah.

\section{Saluran Pemasaran IV}

Saluran pemasaran IV terdiri dari : nelayan $\rightarrow$ TPI $\rightarrow$ pedagang besar $\rightarrow$ rumah makan luar daerah. Pada saluran pemsaran keempat ini terdapat dua lembaga pemasaran diantara nelayan dan rumahmakan luar daerah, yaitu TPI dan pedagang besar. Ikan Kakap yang diperjualbelikan di TPI pada saluran pemsaran keempat ini berjumlah $90 \mathrm{~kg}$ pada level satu seharga Rp 45.000,-/kg. Pedangang besar menjual langsung ke rumah makan yang ada di luar daerah dengan harga $\mathrm{Rp} 60.000,-/ \mathrm{kg}$. Tingginya harga yang diberikan pedagang besar kepada rumah makan daerah dibandingkan pedagang besar menjual kepada pengecer luar daerah pada saluran ketiga. Hal ini dikarenakan selain biaya operasional pengiriman ikan yang dikeluarkan oleh pedagang besar langsung kepada rumah makan daerah dan pedagang pengecer luar daerah membeli langsung kepada pedagang besar sehingga pedagang besar memberikan harga tidak tinggi dibandigkan pada rumah makan daerah.

Minat konsumen terbesar terhadap Ikan Kakap Merah dari TPI Karangsong adalah konsumen luar daerah dibandingkan di dalam daerah. Hal ini terlihat pada saluran pemasaran ketiga, lebih dari Ikan Kakap Merah setengah yang diperjualbelikan (52,35\%), yaitu sebanyak $190 \mathrm{~kg}$ dari total keempat saluran pemasaran $370 \mathrm{~kg}$ yang diperjualbelikan. Kemudian konsumen rumah makan luar daerah $(24,32 \%)$ pada saluran keempat, disusul saluran pertama $(18,92 \%)$ dan saluran kedua $(4,05 \%)$. 


\section{Variabel Biaya Pemasaran}

Setiap lembaga pemasaran melakukan fungsi pemasaran berkaitan dengan biaya yang dikeluarkan berdasarkan volume produk yang diperjualbelikan. Adapun biaya - biaya yang dikelurakan oleh lembaga pemasaran dalam saluran pemasaran Ikan Kakap Merah adalah biaya pengangkutan, biaya penanggungan resiko, biaya tenaga kerja, biaya pengemasan, biaya es batu, dan biaya retribusi/lainnya. Besarnya biaya pemasaran Ikan Kakap Merah disajikan pada Tabel 1.

Data pada Tabel 1 menunjukkan bahwa biaya total pada saluran ketiga lebih besar daripada saluran lainnya, sebesar Rp 3.232. Sedangkan total biaya tertinggi berdasarkan dari harga beli konsumen terakhir adalah pada saluran pemasaran pertama, yaitu 6,05\% (Rp 2.775,-). Kemudian disusul pada saluran pemasaran ketiga, yaitu 5,88\% (Rp 3.232). Hal ini dikarenakan terdapat empat lembaga pemasaran yang terlibat, yaitu nelayan, TPI, pedangang besar, dan pedagang pengecer.

\section{Margin, Biaya, Keuntungan}

Proses mengalirnya barang dari produsen ke konsumen memerlukan biaya, dengan adanya biaya pemasaran maka suatu produk akan lebih tinggi harganya. Lembaga pemasaran yang terlibat dalam proses pemasaran mempunyai tujuan untuk memperoleh keuntungan. Keuntungan pemasaran diperoleh dari pengurangan margin pemasaran terhadap biaya pemasaran yang dikeluarkan. Margin pemasaran diperoleh dari perbedaan harga beli dan harga jual suatu produk untuk pedagang. Sedangkan nelayan (produsen), nilai margin diperoleh dari harga jual terhadap biaya produksi. Margin, biaya, dan keuntungan pemasaran Ikan Kakap Merah tersaji pada Tabel 1.

\section{Tabel 1. Biaya Pemasaran Ikan Kakap Merah}

\begin{tabular}{|c|c|c|c|c|c|}
\hline \multirow[t]{2}{*}{ Komponen Biaya } & \multirow[t]{2}{*}{ Satuan } & \multicolumn{4}{|c|}{ Saluran Pemasaran } \\
\hline & & I & II & III & IV \\
\hline \multirow[t]{2}{*}{ Transportasi } & $\mathrm{Rp} / \mathrm{Kg}$ & 165 & 137 & 237,5 & 225 \\
\hline & & $(0,36)$ & $(0,27)$ & $(0,43)$ & $(0,38)$ \\
\hline \multirow[t]{2}{*}{ Resiko } & $\mathrm{Rp} / \mathrm{Kg}$ & 4,29 & - & 4,78 & 4,5 \\
\hline & & $(0,01)$ & - & $(0,01)$ & $(0,01)$ \\
\hline \multirow[t]{2}{*}{ Tenaga Kerja } & $\mathrm{Rp} / \mathrm{Kg}$ & 80,00 & 80,00 & 26,72 & 22,5 \\
\hline & & $(0,17)$ & $(0,16)$ & $(0,05)$ & $(0,04)$ \\
\hline \multirow[t]{2}{*}{ Pengemasan } & $\mathrm{Rp} / \mathrm{Kg}$ & 45,71 & - & 45,71 & - \\
\hline & & $(0,10)$ & - & $(0,08)$ & - \\
\hline Es Batu & $\mathrm{Rp} / \mathrm{Kg}$ & 52,39 & 9,00 & 138,5 & 81,00 \\
\hline
\end{tabular}




\begin{tabular}{|c|c|c|c|c|c|}
\hline & & $(0,11)$ & $(0,02)$ & $(0,25)$ & $(0,14)$ \\
\hline \multirow[t]{2}{*}{ Retribusi/Lainnya } & $\mathrm{Rp} / \mathrm{Kg}$ & 2.427 & 2.400 & 2.779 & 2.700 \\
\hline & & $(5,29)$ & $(4,80)$ & $(5,05)$ & $(4,50)$ \\
\hline \multirow[t]{2}{*}{ Total } & $\mathrm{Rp} / \mathrm{Kg}$ & 2.775 & 2.626 & 3.232 & 3.033 \\
\hline & & $(6,05)$ & $(5,25)$ & $(5,88)$ & $(5,06)$ \\
\hline \multicolumn{2}{|c|}{ Harga beli Konsumen Akhir } & 45.857 & 50.000 & 55.000 & 60.000 \\
\hline
\end{tabular}

Keterangan : - : Tidak mengeluarkan biaya yang dimaksud

( ) : Persentase terhadap harga beli konsumen akhir

Data hasil analisis margin pemasaran dan keuntungan pemasaran terlihat pada Tabel 2 menunjukkan bahwa total margin terbesar pada saluran pemasaran IV sebesar Rp 59.427,$/ \mathrm{kg}$ yang terbentuk dari setiap lembaga pemasaran yang terlibat (nelayan-TPI-pedagang besar). Pedagang besar memasarkan Ikan Kakap Merah level pertama seharga Rp 60.000,/kg dengan total biaya yang dikeluarkan $\mathrm{Rp} 3.033,-/ \mathrm{kg}$ ke rumah makan luar daerah dari harga beli di TPI Rp 45.000,-/kg. Keuntungan tertinggi pada saluran yang terpendek, yaitu saluran pemasaran IV pula sebesar Rp 56.394/kg dibandingkan saluran pemasaran lainnya. Sama halnya dengan Harifuddin, et al. (2011) yanag menyatakan bahwa saluran terpendek lebih menguntungkan jika dibandingkan dengan saluran yang lebih panjang

Ini menunjukkan bahwa pedagang besar menjual Ikan Kakap Merah dengan harga tinggi karena menanggung risiko rugi yang tinggi pula, dimana membutuhkan sarana dan fasilitas yang menunjang sebagai biaya operasional dan sampai tempat tujuan harus dalam kondisi segar dengan kualitas prima karena sangat dibutuhkan di rumah makan.

\section{Efisiensi Pemasaran}

Efisiensi pemasaran Ikan Kakap Merah dapat dihitung berdasarkan fishman's share nilai efisiensi, terlihat pada Tabel 2. Analisis fisherman's share, yaitu perbandingan harga yang diterima nelayan (produsen) terhadap harga yang diterima konsumen akhir. Pada Tabel 2 menunjukkan nilai fishman's share tertinggi pada saluran pemasaran I (nelayan-TPIpedagang besar-pengecer-konsumen) sebesar $87,23 \%$ artinya bagian yang diterima nelayan dari harga yang dibayarkan konsumen atau pengaruh nelayan terhadap pembentukan harga sebesar $87,23 \%$. Saluran pemasaran I ini dapat dikatakan paling efisien karena margin dan biaya pemasaran paling kecil $\mathrm{Rp} 45.284,-/ \mathrm{kg}$ dan $\mathrm{Rp} 2.775,-/ \mathrm{kg}$ dengan nilai fishman's share besar dibandingkan saluran pemasaran lainnya. Ini sama halnya dengan hasil penelitian yang dilakukan Desvi (2014) menyatakan bahwa efisien pemasaran dilihat dari nilai margin yang rendah, biaya rendah, keuntungan tinggi, danfarmer's share memberikan nilai yang tinggi. Nilai ratio keuntungan dan biaya yang terkecil akan lebih baik karena keuntungan diberikan 
merata (adil) pada setiap lembaga dan dapat dikatakan paling efisien. Haryanti, et al. (2015) menyebutkan bahwa pemasaran ikan patin di Cindai Alus Kabupaten Banjar Provinsi Kalimantan Selatan adalah paling efisien ditandai dengan nilai farmer's share tertinggi sebesar $87,26 \%$.

Tabel 1. Margin, Biaya, Keuntungan, Farmer's Share, dan Efisiensi Lembaga Pemasaran Ikan Kakap Merah Pada Saluran Pemasaran I, II, III, dan IV

\begin{tabular}{|c|c|c|c|c|c|c|c|c|}
\hline \multirow{2}{*}{ Unsur Margin } & \multicolumn{2}{|c|}{ Saluran I } & \multicolumn{2}{|c|}{ Saluran II } & \multicolumn{2}{|c|}{ Saluran III } & \multicolumn{2}{|c|}{ Saluran IV } \\
\hline & $(\mathrm{Rp} / \mathrm{Kg})$ & $(\%)$ & $(\mathrm{Rp} / \mathrm{Kg})$ & $(\%)$ & $(\mathrm{Rp} / \mathrm{Kg})$ & $(\%)$ & $(\mathrm{Rp} / \mathrm{kg})$ & $(\%)$ \\
\hline \multicolumn{9}{|l|}{ Nelayan } \\
\hline Harga Jual & 40.000 & 87,23 & 40.000 & 80,10 & 45.000 & 81,82 & 45.000 & 75,00 \\
\hline Biaya Produksi & 573 & 1,25 & 573 & 1,15 & 573 & 1,04 & 573 & 0,96 \\
\hline Biaya Pemasaran & 1.200 & 2,62 & 1.200 & 2,40 & 1.350 & 2,45 & 1.350 & 2,25 \\
\hline Margin & 39.427 & 85,98 & 39,427 & 78,85 & 44.427 & 80,78 & 44.427 & 74,05 \\
\hline Keuntungan & 38.227 & 83,36 & 38.227 & 76,45 & 43.077 & 78,32 & 43.077 & 71,80 \\
\hline \multicolumn{9}{|l|}{ Pedagang Besar } \\
\hline Harga Beli & 40.000 & 87,23 & 40.000 & 80,00 & 45.000 & 81,82 & 45.000 & 75,00 \\
\hline Harga Jual & 42.000 & 91,99 & 50.000 & 100 & 50.000 & 90,91 & 60.000 & 100 \\
\hline Biaya Pemasaran & 1,490 & 3,25 & 1.426 & 2,85 & 1.704 & 310 & 1.683 & 2,81 \\
\hline Margin & 2.000 & 4,36 & 10.000 & 20,00 & 5.000 & 9,09 & 15.000 & 25,00 \\
\hline Keuntungan & 510 & 1,11 & 8.574 & 15,15 & 3.296 & 5,99 & 13.317 & 22,20 \\
\hline \multicolumn{9}{|c|}{ Pedagang Pengecer Daerah } \\
\hline Harga Beli & 42.000 & 91,59 & - & - & - & - & - & - \\
\hline Harga Jual & 45.857 & 100 & - & - & - & - & - & - \\
\hline Biaya Pemasaran & 84.57 & 0,18 & - & - & - & - & - & - \\
\hline Margin & 3.857 & 8,41 & - & - & - & - & - & - \\
\hline Keuntungan & 3.772 & 8,23 & - & - & - & - & - & - \\
\hline \multicolumn{9}{|l|}{$\begin{array}{l}\text { Pedagang Pengecer Luar } \\
\text { Daerah }\end{array}$} \\
\hline Harga Beli & - & - & - & - & 50.000 & 90,91 & - & . \\
\hline Harga Jual & - & - & - & - & 55.000 & 100 & - & - \\
\hline Biaya Pemasran & - & - & - & - & 178 & 0,32 & - & - \\
\hline Margin & - & - & - & - & 3.000 & 9,09 & - & - \\
\hline Keuntungan & - & - & - & - & 4.822 & 8,77 & - & - \\
\hline Harga Beli Konsumen & 45.817 & 100 & 50.000 & 100 & 55.000 & 100 & 60.000 & 100 \\
\hline Total Margin & 45.284 & 98,75 & 49.427 & 98,85 & 54.427 & 98,96 & 59.427 & 99,05 \\
\hline Total Biaya Pemasaran & 2.775 & 6,05 & 2.626 & 5,25 & 3.232 & 5,88 & 3.033 & 5,06 \\
\hline Total Keuntungan & 42.509 & 92,70 & 46.801 & 93,60 & 51.192 & 93,08 & 56.394 & 93,99 \\
\hline Fishman's Share (\%) & 87,23 & & 80,00 & & 81,82 & & 75,00 & \\
\hline Efisiensi (\%) & 6,05 & & 5,25 & & 5,88 & & 5,06 & \\
\hline
\end{tabular}

Sumber : data primer, diolah 2016

Pada saluran pemasaran I menunjukkan panjangnya rantai pasar dibandingkan saluran lainnya tetapi memberikan nilai fishman's share tertinggi dan paling efisien. Selain itu, kondisi ini berarti memberikan bagian yang adil di setiap lembaga pemasaran pada saluran pemasaran I. Sesuai dengan pernyataan dari Mubiyarto (1994) bahwa saluran pemasaran yang adil adalah yang dapat memberikan bagian yang adil pada setiap lembaga pemasaran yang ada. Sedangkan hasil penelitian Purnomo (2018) berbanding terbalik 
dengan hasil penelitian ini bahwa pemasaran ikan yang paling efisien pada fishman's share teritnggi 95\% yang diperoleh dari saluran pemasaran I (nelayan-TPI-konsumen akhir) adalah saluran terpendek. Begitu pula dengan Sarwanto, et al., (2014) menyatakan bahwa tipe 1 (nelayan-konsumen) merupakan saluran pemasaran paling efisien dengan nilai farmer's share paling tinggi yaitu sebesar $85,6 \%$. Saluran pemasaran ikan tongkol pola I(nelayanpedagang pengecer-konsumen) di Desa Seraya Timur merupakan pola saluran pemasaran yang paling efisien dan paling yang pendek, memiliki marjin pemasarn terkecil Rp 5.000/kg dan fishman's share terbesar 75,00\% dari pola saluran pemasaran lainnya (Nuriati, 2018). Dengan demikian, efisien dan tidaknya saluran pemasaran ikan tidak dilihat dari panjang atau pendeknya saluran pemasaran

Data pada Tabel 2 menunjukkan bahwa semua saluran pemasaran Ikan Kakap Merah adalah efisien karena nilainya kurang dari 50\%, jika dilihat dari nilai efisiensi pemasaran yaitu perbandingan biaya pemasaran terhadap nilai produk yang diperjualbelikan. Hal ini menunjukkan semakin kecil biaya yang dikeluarkan dan semakin besar nilai produk yang diperjualbelikan. Saluran pemasaran Ikan Kakap Merah yang paling efisiensi adalah saluran pemasaran IV sebesar 0,05 jika dilihat dari paling kecilnya nilai efisiensi pemasaran. Hal ini sesuai dengan Hapsari (2013) menyatakan bahwa pemasaran ikan tongkol di wilayah kerja TPI Ujung Batu, Jepara adalah efisien di setiap lembaga pemasaran, yang paling efisien pada lembaga pemasaran di tingkat pedagang besar 3,2\% (0,032) dibandingkan di tingkat pengecer $3,3 \%(0,033)$.

\section{KESIMPULAN}

Saluran pemasaran Ikan Kakap di wilayah kerja TPI Karangsong Kabupaten Indramayu terdapat empat saluran. Pola saluran pemasaran I : nelayan-TPI-pedagang besar-

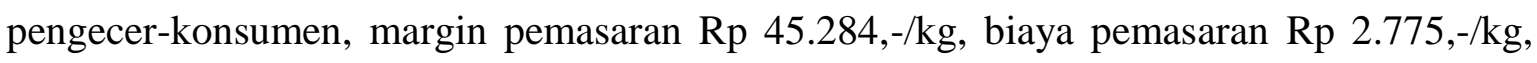
keuntungan Rp 42.509,-/kg, fishman's share 87,23\%, dan Ep 6,05\%. Pola saluran pemasaran II : nelayan-TPI-pedagang besar-rumah makan daerah, margin pemasaran Rp 49.427,-/kg, biaya pemasaran $\mathrm{Rp} 2.626,-/ \mathrm{kg}$, keuntungan $\mathrm{Rp} 46.801,-/ \mathrm{kg}$, fishman's share 80,00\%, dan Ep 5,25\%. Saluran pemasarn III ; nelayan-TPI-pedagang besar-pengecer luar daerahkonsumen, margin pemasaran Rp 54.427,-/kg, biaya pemasaran Rp 3.232,-, keuntungan Rp $51.192,-/ \mathrm{kg}$, fishman's share 81,82\%, dan Ep 5,88\%. Saluran pemasaran IV : nelayan-TPIpedagang besar- rumahmakan luar daerah, margin pemasaran Rp 59.427,-/kg, biaya pemasaran Rp 3.033,-/kg, keuntungan Rp 56.394,-/kg, fishman's share 75,00\%, dan Ep 
$5,06 \%$. Saluran pemasaran yang paling efisien adalah saluran pemasaran I memiliki margin paling kecil, biaya pemasran terkecil, fishman's share terbesar. Saran bagi nelayan perlu membentuk kelompok dan kopersai nelayan agar memiliki bargaining power (harga tawar) dalam pengambilan keputusan harga jual Ikan Kakap Merah yang didasari atas informasi harga ikan yang sewaktu-waktu berubah di TPI Karangsong. Selain itu pemasaran dapat dilakukan secara kolektif dan dapat bekerja sama dengan pihak luar atau ketiga antar lemabaga.

\section{DAFTAR PUSTAKA}

Desvi, M. (2014). Analisis Efisiensi Pemasaran Hasil Perikanan Tangkap di Pangkalan Pendaratan Ikan Muara Angke, DKI Jakarta. 58. Retrieved from H14mde.

Dinas Perikanan dan Kelautan Kabupaten Indramayu. (2012). Buku Laporan Tahunan, Indramayu. Penerbit Dinas Perikanan dan Kelautan Kabupaten Indramayu.

Dinas Perikanan dan Kelautan Kabupaten Indramayu. 2014. Data Produksi Perikanan dan Kelautan Tahun 2014. Indramayu. Dinas Perikanan dan Kelautan Kabupaten Indramayu.

Hapsari, T. D. (2014). Distribusi Dan Margin Pemasaran Hasil Tangkapan Ikan Tongkol (Euthynnus affinis) di Tpi Ujungbatu Jepara. AQUASAINS, Vol 2, No 2, Hal 131138.

Harifuddin, Aisyah, \& Budiman (2011). Analisis Margin dan Efisiensi Pemasaran Rumput Laut di Desa Mandalle Kecamatan Mandalle Kabupaten Pangkep. Jurnal Agribisnis, Vol. 10, No 3, Hal 38-48.

Haryanti, D., Mahreda, E. S., \& Mustika, R. (2016). Analisis efisiensi pemasaran ikan patin (Pangasius Sp) di Cindai Alus Kabupaten Banjar Provinsi Kalimantan Selatan. Fish Scientiae, Vol 5, No 9, Hal 47-54.

Huda, M., Solihin, I., \& Lubi, E. (2016). Tingkat Efisien Pemasaran Ikan Laut Segar Di Pelabuhan Perikanan Nusantara (Ppn) Brondong. Jurnal Teknologi Perikanan dan Kelautan, Vol 6, No 1, Hal 91-104.

Koperasi Perikanan Laut Mina Sumitra Kabupaten Indramayu. (2015). Rekap Bulanan Produksi Ikan Tangkap. Indramayu.

Mubyarto. (1994). Pengantar Ekonomi Pertanian. LP3ES. Jakarta.

Nazir, M. (2011). Metode Penelitian. Jakarta: Ghalia Indonesia.

Nuriati, N. K. Et al. (2017). Hasil Tangkapan Nelayan Di Desa Seraya Timur Kecamatan Karangasem. Jurnal Jurusan Pendidikan Ekonomi, 10(2), 1-11. 
Purnomo, C. (2018). Pola Saluran Pemasaran Ikan Di Daerah Istimewa Yogyakarta (DIY). Majalah Ilmiah Bahari Jogja, 16(2), 126-147.

Rahim, A \& Hastuti, D. R. D. (2007). Ekonomika Pertanian. Jakarta: Penebar Swadaya.

Sarwanto, C., Wiyono, E. S., Nurani, T. W., \& Haluan, J. (2014). Kajian Sistem Pemasaran Ikan Hasil Tangkapan Nelayan Di Kabupaten Gunungkidul, Provinsi DIY. Jurnal Sosial Ekonomi Kelautan dan Perikanan, Vol 9, No 2, Hal 207-217.

Soekartawi. (2002). Prinsip Dasar Ekonomi Pertanian, Teori dan Aplikasi. PT Raja Grafindo Persada. Jakarta.

Sugiono. (2009). Metode Penelitian Kuantitatif dan Kualitatif. Bandung: Alfabeta. 